\title{
Ciddi varus dizilim bozukluğu olan dizlerde çift seviye (ikili) osteotomi
}

\section{Double-level osteotomy in knees with severe varus alignment disorder}

\author{
Kürşad Aytekin ${ }^{1}$, Orhan Balta², Bora Bostan ${ }^{3}$ \\ ${ }^{1}$ Giresun Üniversitesi Tıp Fakültesi, Ortopedi ve Travmatoloji Anabilim Dalı, Giresun \\ ${ }^{2}$ Tokat Gaziosmanpaşa Üniversitesi Tıp Fakültesi, Ortopedi ve Travmatoloji Anabilim Dalı, Tokat \\ ${ }^{3}$ Özel Medical Palace Hastanesi, Kayseri, Ortopedi ve Travmatoloji Kliniği, Kayseri
}

Alt ekstremite dizilim bozuklukları osteoartrite ilerlemeyi artırmaktadır. Bu amaçla biyolojik tedavi yöntemlerinden osteotomiler kullanılarak mekanik aks restorasyonu sağlanır ve deformite düzeltilir. İleri varus deformitesi hastalarında tek seviyeli osteotomi uygulamaları mekanik aksı düzeltebilir. Ancak eklem çizgisinin yere paralelliğini bozup eklem oblikliğine sebep olabilir. Eklem çizgisinin oblikitesi makaslama kuvvetlerinin etkisi ile osteoartrite ilerlemeyi hızlandırmaktadır. Dolayısı ile ileri varus deformitelerinde eklem çizgisinin horizontal plana paralelliğini sağlamak mekanik aksın restorasyonu kadar önemlidir. Eklem oblikliğini engelleme amacı ile diz çevresine ikili osteotomiler kullanılmaktadır. Bu yazıda alt ekstremite fizyolojik dizilimi ve biyomekaniği ışığında, diz çevresine uygulanabilen ikili osteotomi tarihçesi, gereklilikleri, osteotomi seçenekleri, implant seçenekleri ve cerrahi seçenekler incelenmiştir.

Anahtar sözcülkler: ileri varus deformitesi; eklem oblikitesi; çift osteotomi

\begin{abstract}
Lower limb malalignment contributes to the progression to osteoarthritis. Mechanical axes restoration by deformity correction is performed by osteotomies around the knee. Single osteotomy in patients with advanced varus deformity can correct the mechanical axis. However, it may cause joint line obliquity. The obliquity of the joint line accelerates progression of osteoarthritis due to shear forces on the cartilage. Therefore, in advanced varus deformities, ensuring parallelism of the joint line to the horizontal plan is as important as the restoration of the mechanical axis. Double osteotomies are used around the knee to prevent joint obliquity. In this article, in the light of the physiological alignment and biomechanics of the lower limbs; the history of double osteotomies, indications, osteotomy options ant implants were discussed.
\end{abstract}

Key words: advanced varus deformity; joint obliquity; double osteotomy

şöyle aktarmıştır; genu varumda osteotomi sonrası eklem çizigsi yere paralel olmakta ancak genu valgumda osteotomi sonrası eklem çizgisi oblik olmaktadır. ${ }^{[4]} \mathrm{Bu}$ durum çift osteotomileri gerektirmedir. Deformite düzeltme temel prensipleri 1964'te Friedrich Pauwels ve 1976 'da Paul Maquet tarafından tanımlandı. Çift seviye osteotomiyi ilk tanımlayan 1969 yılında Benjamin ve ark.'dır. ${ }^{[5]}$ Diz çevresinde gerçekleştirilen osteotomilerin amacı yük aktarım ekseninde değişiklik yaparak, hasarlı eklem yüzeyine gelen mekanik stresi eklemin karşı tarafına aktarıp diz ekleminin sağ kalımını artırmaktır. Çift seviyeli osteotomilerde ise amaç etkilenmiş eklemi yükten kurtarmaktan başka, eklem uyum açısını düzelterek eklem hattını yere paralel hale getirmektir.

- İletişim adresi: Kürşad Aytekin, PhD, Giresun Üniversitesi Tıp Fakültesi, Ortopedi ve Travmatoloji Anabilim Dalı, Debboy, Giresun Tel: 0454 - 3101600 e-posta: kursadaytekin@gmail.com

- Geliș tarihi: 18 Subat $2020 \quad$ Kabul tarihi: 5 Mart 2020 
Günümüzde ostetomiler en sık diz çevresinde kullanılmaktadır. Temel olarak diz çevresi osteotomileri tek kompartmanlı osteoartrit tedavisinin yanında genu valgum, travma sonrası deformiteler, raşitizm, doğumsal deformiteler, büyüme plağı hastalıkları, metabolik sorunlar, osteopatiler (renal osteodistrofi vb.), miyopatik ve nörolojik hastalıklar, posttravmatik deformiteler, tümör, osteonekroz, ve diğer diz çevresi deformiteleri için kullanılmaktadır. Diz çevresi osteotomilerini frontal, sagittal ve aksiyel planda değerlendirmek gerekir. Femur ve tibia kombine deformitesinde her ikisinin de düzeltilmesi gerekir. Aksi takdirde yeni kemik deformiteleri yaratılır. Sadece bir segmentin düzeltilmesi (tibia veya femur) bacak ekseni düzeltirken eklem hattının patolojik değişimi ile sonuçlanır. Saragaglia ve ark. doğru dizilimi elde etmek için navigasyon kullanmışlardır. ${ }^{[6]}$ Ameliyat öncesi planlamada açık kama yüksek tibial osteotomi similasyonunda mekanik aks düzeltmek için mMPTA $>93^{\circ}$ üzerine çıkılması gerekiyor ise ve mevcut $\mathrm{mLDFA}>90^{\circ}$ ise distal femur osteotomisi için bir gösterge olup bu durumda çift seviyeli osteotomi akılda tutulmalıdır. ${ }^{[6-8]}$ Tek seviyeli osteotomi ile $4^{\circ}$ 'den fazla eklem eğriliği oluşuyorsa çift seviyeli osteotomi daha iyi bir tercih olarak karşımıza çıkmaktadır. ${ }^{\left[{ }^{8]}\right.}$ Yapılan çalışmalarda $5^{\circ}$ 'den fazla eklem çizigisi eğikliği eklem kıkırdağına yüklenen stresi artırmaktadır. ${ }^{[9]}$ Kamara ve ark., varus deformiteli dizlerde yüksek tibial osteotomi ve çift seviyeli osteotomiyi karşılaştırdıkları çalışmalarında, çift seviyeli osteotominin hem tibiada hem de femurda fizyolojik torsiyonu artırırken sadece yüksek tibial osteotominin rotasyonel dizilimi değiştirmediğini saptamışlardır. ${ }^{[10]}$

Bu yazıda hedefimiz ortoröntgenografi ile alt ekstremitede dizilimini değerlendirmek, diz çevresinde çift osteotomi uygulama endikasyonlarını, hasta seçimini, preoperatif (ameliyat öncesi) planlamayı, ostetotomi seçimini, osteotomi tekniklerini, tespit materyali seçimini, ameliyat sonrası rehabilitasyonu ve takiplerde gözlenebilecek olası komplikasyonları tartışmaktır.

\section{Ortoröntgenografi ile Alt Ekstremite Diziliminin Değerlendirmesi ve Deformitenin Tespiti}

Alt ekstermitede dizilimi değerlendirmek için uygun bir ortoröntgenografi çekilmelidir. Bu amaçla hasta ayakta basarak alt ekstremite yük altında olmalıdır. Kasetin röntgen tüpüne mesafesi $305 \mathrm{~cm}$ olmalıdır. Ayrıca alt ekstremite pozisyonu önemlidir. Patella orta hatta iken çekim yapılmalıdır.

Ortoröntgenografinin değerlendirilebilmesi için çekilen grafide femur başı, diz eklemi, ayak bilek eklemi ayırt edilebilir olmalıdır (Şekil 1). ${ }^{[11]}$ Değerlendirmeye başlayınca femur başının orta noktasına ve talus kubbesinde eklem yüzünün orta noktasına işaret konulur ve bu iki

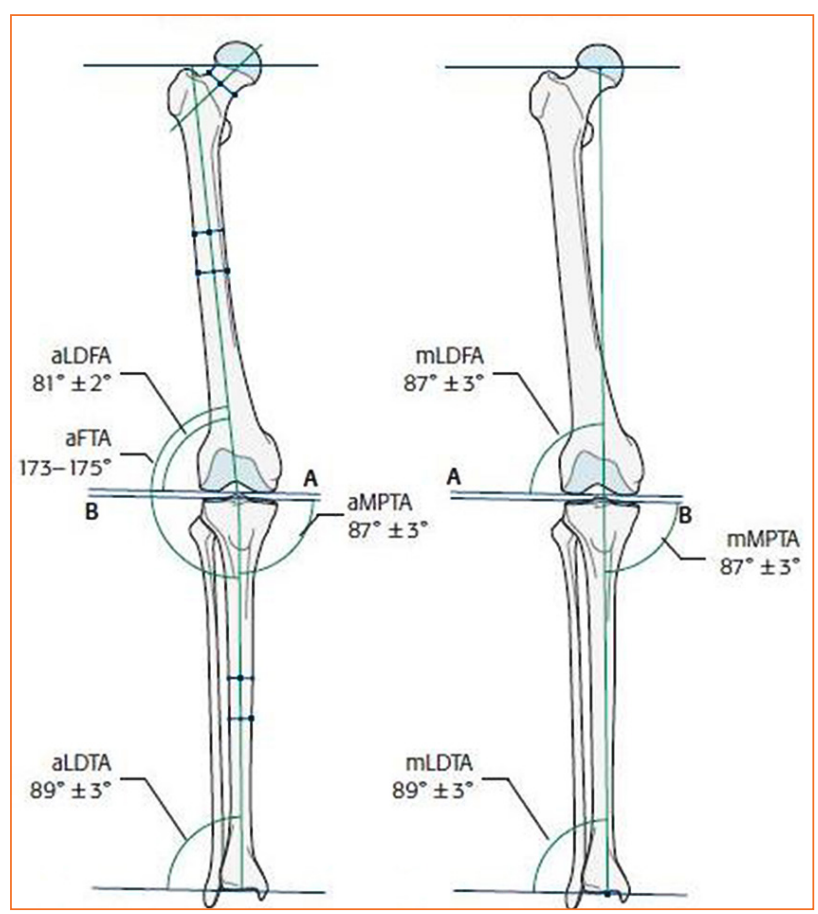

Şekil 1. Alt ekstremitenin anatomik ve mekanik aksları ile fizyolojik açılarının hesaplanması. ${ }^{[11]}$

nokta bir çizgi ile birleştirilir. Bu vektörel çizgi alt ekstremitenin mekanik aksı (Mikulicz çizgisi) olarak isimlendirilir. Mekanik aks diz ekleminde tibia platosunun ortasından geçer. Mekanik aks fizyolojik olarak diz ekleminin merkezinden veya ortalama $4( \pm 2) \mathrm{mm}$ medialinden ya da lateralinden geçebilir. ${ }^{[12]}$ Mekanik aks bu sınırların dışından ilerliyorsa, valgus veya varus deformitesi mevcuttur. Alt ekstremitenin mekanik aksından (Mikulicz çizgisi) başka femurun ve tibianın da mekanik aksları mevcuttur (Tablo 1). Femur mekanik aksı, femur başının ortasından diz ekleminin ortasına çekilen vektörel çizgi ile belirlenir. Diz ekleminin ortasını hesaplamak için öncelikle femur kondillerinin en distalini teğet geçen eklem çizgisi çizilir. Kondillere temas noktalarının tam ortası eklemin orta noktası kabul edilir. Femurun anatomik aksını belirlemek için femur gövdesinin en az iki farklı bölgesinde medial korteksten lateral kortekse horizontal planda düz bir çizgi çizilir. Bu çizgilerin orta noktasından başlayıp eklem ortasından geçen vektörel çizgi anatomik aksı oluşturur. Mekanik femur aksı ile anatomik femur aksı arasında $6^{\circ} \pm 1^{\circ}$ 'lik fark vardır ve bu açıya anatomikmekanik femoral açı (amFA) denir. Radyolojik muayenede bu aksların eklem çizgisi ile lateralde yaptıkları açı kullanılır. Mekanik lateral distal femoral açı (mLDFA) ortalama $87^{\circ} \pm 3^{\circ}$, anatomik lateral distal femoral açı (aLDFA) ortalama $81^{\circ} \pm 2^{\circ} \mathrm{dir}$ (Tablo 1 ). 
Tablo 1. Sağlıklı alt ekstremitede yük altında çekilen ortoröntgenografilerde tanımlanan açılar ve normal değerleri

\begin{tabular}{lcc}
\hline Açının adı & Kısaltma & Normal değerler \\
\hline Anatomik femorotibial açı & aFTA & $173-175^{\circ}$ \\
Anatomik-mekanik femoral açı & amFA & $6^{\circ} \pm 1^{\circ}$ \\
Anatomik lateral distal femoral açı & aLDFA & $81^{\circ} \pm 2^{\circ}$ \\
Mekanik lateral distal femoral açı & mLDFA & $87^{\circ} \pm 3^{\circ}$ \\
Anatomik medial proksimal tibial açı & aMPTA & $87^{\circ} \pm 3^{\circ}$ \\
Mekanik medial proksimal tibial açı & mMPTA & $87^{\circ} \pm 3^{\circ}$ \\
Anatomik lateral distal tibial açı & aLDTA & $89^{\circ} \pm 3^{\circ}$ \\
Mekanik lateral distal tibial açı & mLDTA & $89^{\circ} \pm 3^{\circ}$
\end{tabular}

Tibiada mekanik ile anatomik akslar paraleldir ancak mekanik aks birkaç milimetre daha medialde yer alır. Eminenslerin orta noktasından talus kubbesinin ortasına çekilen çizgi mekanik aksı gösterir. Bu aksın tibia platosu ile medialde yaptığı açıya mekanik proksimal tibial açı (mMPTA) veya anatomik proksimal tibial açı (aMPTA) denilir. Normal değerleri $87^{\circ} \pm 3^{\circ}$ olarak bildirilmiştir. Aksın ayak bileğinden geçen eklem çizgi ile lateralde yaptığı açıya ise mekanik/anatomik lateral distal tibial açı ( $m L D T A / a L D T A)$ denilir ve ortalama olarak normal değeri $89^{\circ} \pm 3^{\circ}$ dir (Tablo 1 ).

Eklemde femur kondillerinin en distalinden teğet geçen çizgi ile tibia platosundan geçen teğet çizgi arasındaki açıya eklem çizgisi yakınsama açısı (JLCA) denilir ve normal sınırları $0^{\circ}-2^{\circ}$ dir (Tablo 1$)$.

Alt ekstremite mekanik aksının diz eklemi merkezine olan mesafesine mekanik aks deviasyonu (MAD) denilir. MAD'nin $15 \mathrm{~mm}$ 'den daha mediale fazla sapması genu varum olarak isimlendirilirken, MAD'nin $10 \mathrm{~mm}$ den daha fazla laterale sapması genu valgum olarak isimlendirilir. Ayrıca femur ile tibianın mekanik aksları arasındaki fark da mekanik femorotibial açı (mFTA) adı altında varus/valgus açısını verir (Şekil 2). ${ }^{[11]}$

\section{Hasta Seçimi ve Ameliyat Öncesi Planlama}

Başarının en önemli faktörü ideal hasta seçimi olarak karşımıza çıkmaktadır. Çift seviyeli osteotomi unikompartmantal diz artritli, özellikle genç, aktif ve ciddi düzeltme gerektiren diz deformiteleri bulanan hastalarda başarılı bir tedavidir. Genel olarak literatürde çift seviyeli osteotomi endikasyonu şiddetli varus şekil bozukluğu (deformitesi) bulunan semptomatik ve medial kompartman osteoartritli hastalardır. ${ }^{[7,13]}$ Yüksek tibial osteotomi tek kompartman artritli ve diğer kompartmanı sağlam olan, $20^{\circ}$ 'den az fleksiyon kontraktürü olan, $100^{\circ}$ 'den fazla fleksiyon yapabilen ve vücut kitle indeksi 30'dan küçük olan hastalarda yaygın olarak kullanılır. Genel olarak erkeklerde 65 yaş altı, kadınlarda 55 yaş altı hastalara önerilmesine rağmen, daha yaşlı hastalarda da başarılı sonuçlar vermektedir. ${ }^{[14,15]}$ Ön çapraz bağın sağlam olma zorunluluğu yoktur. Sigara ve yüksek vücut kitle indeksi komplikasyon ihtimalini artırır.

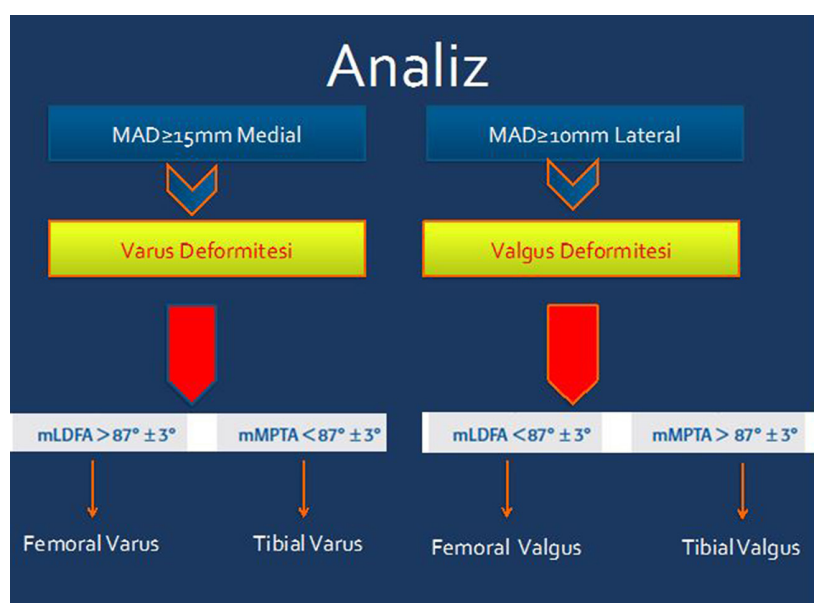

Şekil 2. Mekanik aks deviasyonu ve diz çevresi açı ölçüm sonuçlarına göre deformitenin yerinin tanımlanması. ${ }^{[11]}$ 
Diz çevresi deformitelerinde düzeltme hedefleri; artrozu olmayan dizlerde normal fizyolojik dizilimin sağlanması, medial kompartman artrozu varlığında Fujisawa noktasi, artritik valgus dizlerde ise nötral veya hafif varus dizilimi elde etmektir.

Alt ekstremitede frontal plandaki deformiteleri düzeltmek ve MAD/mFTA'nın restorasyonu tek başına yeterli olmayabilir. Diz ekleminin yere paralel olması bir mecburiyettir. Oblik bir eklem hattı makaslama kuvvetleri nedeniyle diz ekleminde instabilite ile beraber osteoartrite neden olabilir. ${ }^{[7,16]}$ Preoperatif (Ameliyat öncesi) planlamada osteotomi sonrası elde edilecek açılar göz önünde bulundurulmalıdır. Şayet ölçülen mMPTA ve mLDFA normal sınırlarının dışında ise diz çevresine çift osteotomi gerekir (Şekil 2). ${ }^{[11]}$ Bunlardan bir tanesi distal femurda mLDFA açısının restorasyonu için diğeri ise proksimal tibiada mMPTA açısının restorasyonu için yapılır. Kaynama sonrası elde edeceğimiz dizilim ile diz eklem çizgisi horizontal plana paralel kalmalıdır. Cift seviyeli deformite olmasına rağmen deformite tek seviye ve genellikle tibiadan düzeltilirse eklemde obliklik, kıkırdak üzerinde makaslama kuvvetinde artış ve artroz ile sonuçlanması kaçınılmazdır. ${ }^{[7]}$ Bu durumda bir diğer problem ise daha sonra yapılacak diz protezi için ciddi kemik stok kaybıdır. ${ }^{[8]}$

Cift seviyeli (femur ve tibia) osteotomisi için ideal endikasyonlardan bir tanesi düşük mMPTA, düşük mLDFA ve yüksek JLCA ile seyreden ve belirgin lateral thrust yürüyüşü yaratan deformitedir.

Genel olarak ileri derecede varus dizlerde en sık kullanılan yöntem lateral kapalı kama femur osteotomisi ve açık kama yüksek tibia osteotomisi iken ileri derece valgus deformitelerinde medial distal femur kapalı kama ve proksimal tibia kapalı kama osteotomisidir. Asağıdaki tabloda muhtemel senaryolarda uygulanabilecek kombine osteotomi seçenekleri sunulmakta$\operatorname{dır}$ (Tablo 2). [11]

\section{Cerrahi Teknik}

Diz çevresindeki düzeltme kabaca femoral veya tibial deformitenin türüne bağlı olarak medial veya lateral olarak ve açık veya kapalı kama tekniğinde yapılabilmektedir. Tibial düzeltme için son zamanlarda medial girişimler ön plana çıksa da literatürde lateral kapalı kama osteomisi, dome osteotomisi, medial açık hemikallotazis, tek planda oblik osteotomi, tek planda transvers osteotomi, biplanar açık kama osteotomisi ve tibial tüberkülün proksimal fragmanda bırakıldığı biplanar osteotomiler gibi birçok osteotomi tanımlanmıştır.

Genel olarak ileri varus deformitesi olan dizlerde son zamanlarda kemik stok temasını fazla olduğu lateral femoral kapalı kama ve medial açık kama tibia osteotomisi tercih edilmektedir. Biplanar distal femur medial kapalı kama osteotomisinde suprapatellar yağ dokusu sağlam olduğu için erken hareket kazanımı, kemik teması fazla olduğu için erken kaynama ve stabilite sağlamaktadır. Lobenhoffer ve ark.'nın ${ }^{[17]}$ popülarize ettikleri tibial tüberkülün distal fragmanda bırakıldığı biplanar medial açık kama osteotomisi avantajı ise greft gerektirmiyor olması ve erken yük verme olarak karşımıza çıkmaktadır.

Cilt insizyonundan 30 dakika önce tek doz antibiyotik profilaksisi uygulanır. Eşlik eden eklem içi patolojileri

Tablo 2. Çift ostetotomi gerektiren vakalarda deformiteye göre olası kombine osteotomi seçenekleri[11]

\begin{tabular}{|c|c|c|c|}
\hline \multirow{2}{*}{$\begin{array}{l}\text { Mekanik aks } \\
\text { deviasyonu }\end{array}$} & \multicolumn{3}{|c|}{ Eklem çizgisi yakınsama açısı (JLCA) } \\
\hline & $\operatorname{Varus}\left(\mathrm{JLCA}>2^{\circ}\right)$ & Nötral (JLCA: $\left.0^{\circ}-2^{\circ}\right)$ & Valgus $\left(\right.$ JLCA < $\left.0^{\circ}\right)$ \\
\hline Varus & $\begin{array}{l}\text { F: Medial kapalı kama DFO * } \\
+ \\
\text { T: Medial açık kama HTO * } \\
{ }^{*} \text { Alternatif: Lateral açık kama DFO }\end{array}$ & $\begin{array}{l}\text { F: Lateral kapalı kama DFO * } \\
+ \\
\text { T: Medial açık kama HTO }\end{array}$ & $\begin{array}{l}\text { F: Lateral kapalı kama DFO } \\
+ \\
\text { T: Medial kapalı kama HTO * } \\
\text { * Alternatif: Lateral açık kama HTO }\end{array}$ \\
\hline Nötral & $\begin{array}{l}\text { F: Medial kapalı kama DFO * } \\
+ \\
\text { T: Medial açık kama HTO } \\
\text { * Alternatif: Lateral açık kama DFO }\end{array}$ & & $\begin{array}{l}\text { F: Lateral kapalı kama DFO } \\
+ \\
\text { T: Medial kapalı kama HTO * } \\
\text { * Alternatif: Lateral açık kama HTO }\end{array}$ \\
\hline Valgus & $\begin{array}{l}\text { F: Medial kapalı kama DFO * } \\
+ \\
\text { T: Medial açık kama HTO } \\
\text { * Alternatif: Lateral açık kama DFO }\end{array}$ & $\begin{array}{l}\text { F: Medial kapalı kama DFO * } \\
+ \\
\text { T: Medial kapalı kama HTO ** } \\
\text { * Alternatif: Lateral açık kama DFO } \\
\text { ** Alternatif: Lateral açık kama HTO }\end{array}$ & $\begin{array}{l}\text { F: Lateral kapalı kama DFO } \\
+ \\
\text { T: Medial kapalı kama HTO * } \\
\text { * Alternatif: Lateral açık kama HTO }\end{array}$ \\
\hline
\end{tabular}



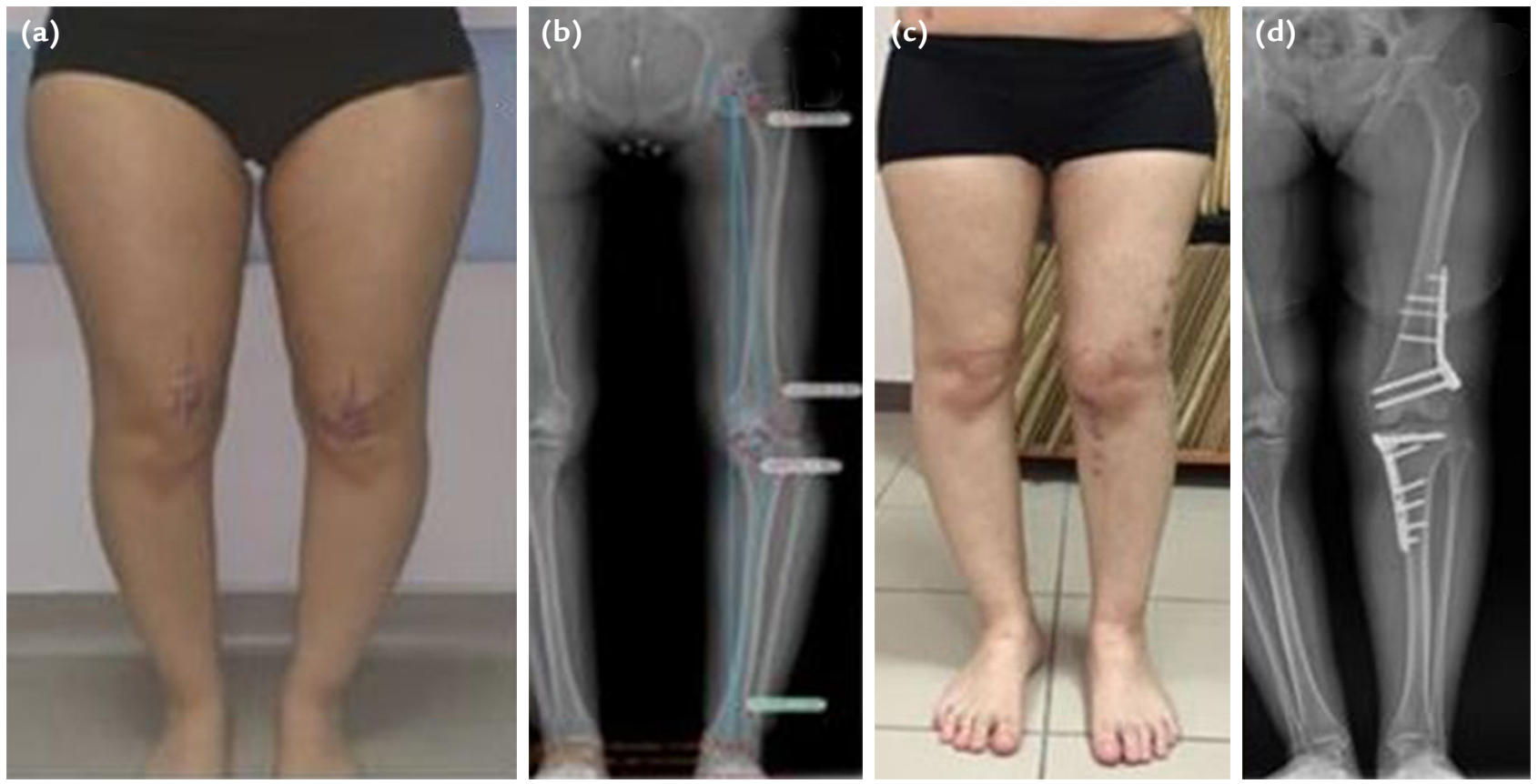

Şekil 3. a-d. Ameliyat öncesi klinik görüntü (a). Ameliyat öncesi ortoröntgenografi (b). Ameliyat sonrası klinik görüntü (c). Ameliyat sonrası ortoröntgenografi (d).

değerlendirmek için osteotomiden önce artroskopi yapılabilir. Artroskopik girişim bize eklem içerisindeki bağ, menisküs, kıkırdak patolojilerinin saptanmasını ve tedavisini sağlar. Hasta radyolusent (ışın geçirgen) bir ameliyat masasında sırtüstü pozisyonda opere edilir.

Femurda da tibiada da osteotomi seçimimizin ne olacağı, deformitenin CORA'sının (Central of Rotation Angle) nerede olduğuna bağlıdır. Örneğin femurda CORA troklea seviyesinde ise suprakondiler biplanar osteotomi kullanılabilir. Kalça hareketleri serbest ve kalça altı yükseltilerek, patella orta hatta olacak şekilde hastaya pozisyon verilir. Kombine osteotomiyi yaparken özellikle kapalı kama femur ve açık kama tibia osteotomisi yapılacak ise önce femur osteotomisi yapılır. Böylece çıkarılan kama tibiadaki osteotomi alanına konulabilir. Yapılan preoperatif planlamaya göre gönderilen $\mathrm{K}$ telleri üzerinden femurda biplanar osteotomi yapılır ve stabil plak osteosentezi gerçekleştirilir. Tibiadaki varus deformitesi genellikle medial açık kama osteotomisi ile gerçekleştirilir. Biplanar açık kama osteotomisi iyi bir seçenektir. Biplanar tibia açık kama osteotomisi tibial tüberkülün distalde bırakıldığı retrotüberkü|[17] osteotomisi seklinde olabileceği gibi, tibial tüberkülün proksimal$\mathrm{de}^{[18]}$ bırakıldığı biplanar osteotomi şeklinde de olabilir. Biz kendi pratiğimizde tibia açık kama osteotomisinde Lobenhoffer'in popülarize ettiği tibial tüberkülün distalde bırakıldığı biplanar osteotomiyi tercih etmekteyiz.
Şayet CORA metafizer bölgeden uzakta kemiğin diafiz (cisim) seviyesinde ise perkütan osteotomi uygulamak kaynama gecikmesi ile enfeksiyon gibi riskleri azaltabilir.

Osteotomi sonrası tespit amacı ile kullanılacak implant, kaynama sonuçlanana kadar erken harekete izin verecek şekilde stabiliteyi sağlamalıdır. Osteotomi hatlarının tespiti için son yıllarda sık kullanılan sabit açılı plak fiksatörler iyi sonuçlar vermektedir.

Hem femuru hem tibiayı içeren çift seviyeli osteotomiler hastanın hareket aralığı kaybına neden olma eğiliminde olduğundan ameliyat sonrası istirahatte bile kalça ve diz $90^{\circ}$ fleksiyon pozisyonunda olmalıdır. Ameliyat sonrası 1. gün dren çekilir. $15 \mathrm{~kg}$ kısmi ağırlık vererek koltuk altı değnekleri ile mobilize edilir. Diz hareketlerini artırıcı ve diz çevresi kasları güçlendirici günlük fizyoterapi egzersizleri başlanır. Genellikle diz hareket aralığını kısıtlamak veya destek için breys uygulamak gerekli değildir. Ameliyat sonrası 1 . hafta ve 6 . haftalarda anteroposterior ve lateral grafi ile radyolojik değerlendirme yapılır. Haftalık yük artırımı yapılarak tam yüke ortalama 6 . haftada geçilir. Hastalar genellikle yaklaşık 10-12 hafta sonra işe dönebilirler.

Diz çevresine çift osteotomi uyguladığımız bir hastanın ameliyat öncesi, ameliyat esnası ve ameliyat sonrası klinik ve radyolojik görüntüleri aşağıda paylaşıımıştır (Şekil 3-5). 


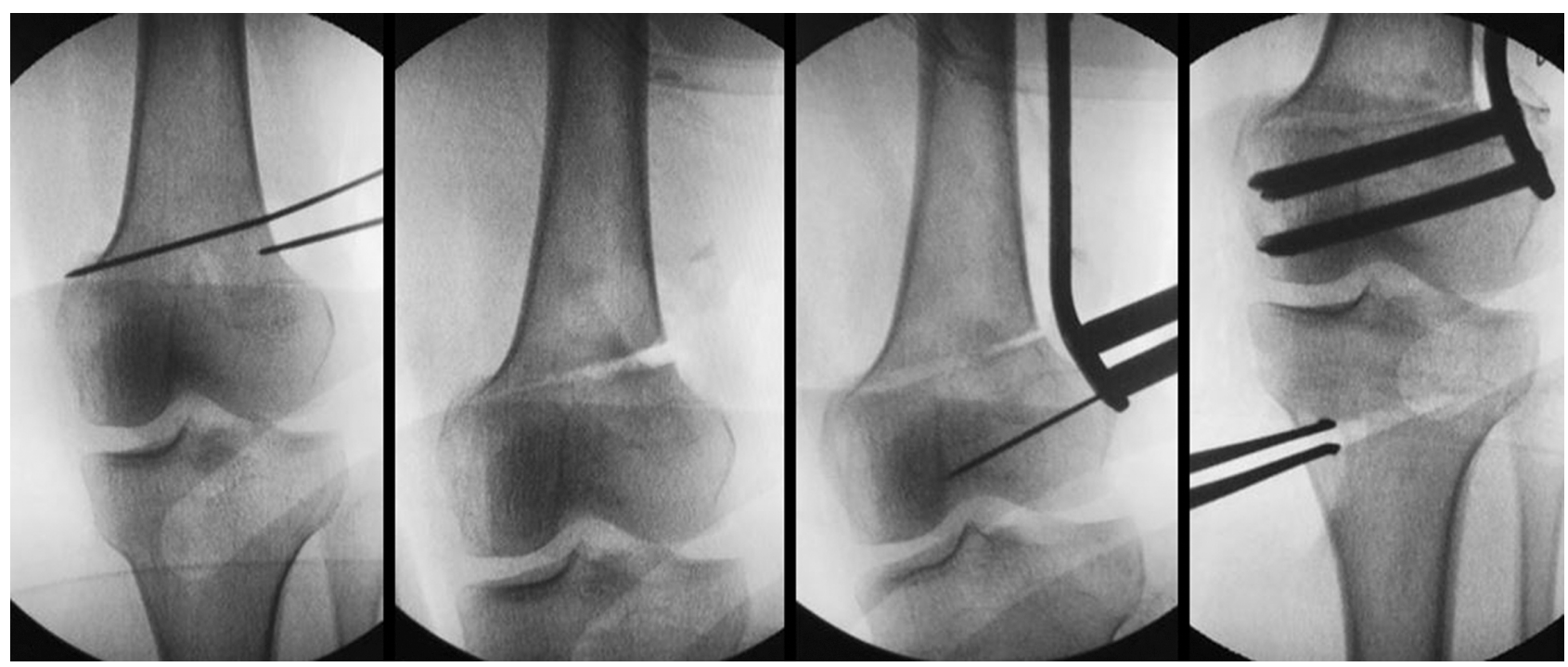

Şekil 4. Ameliyat esnasında çekilen fluoroskopi görüntüleri.
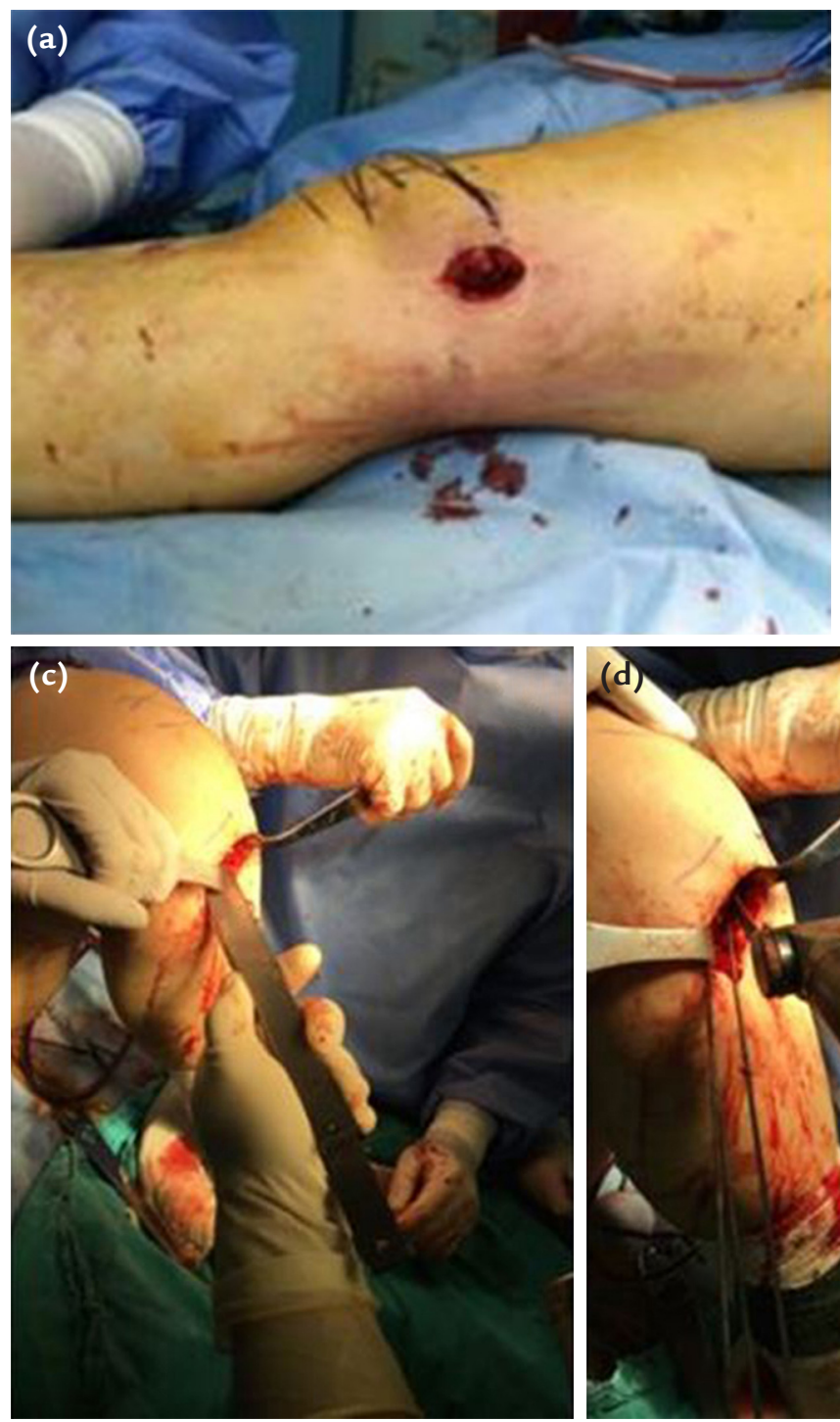

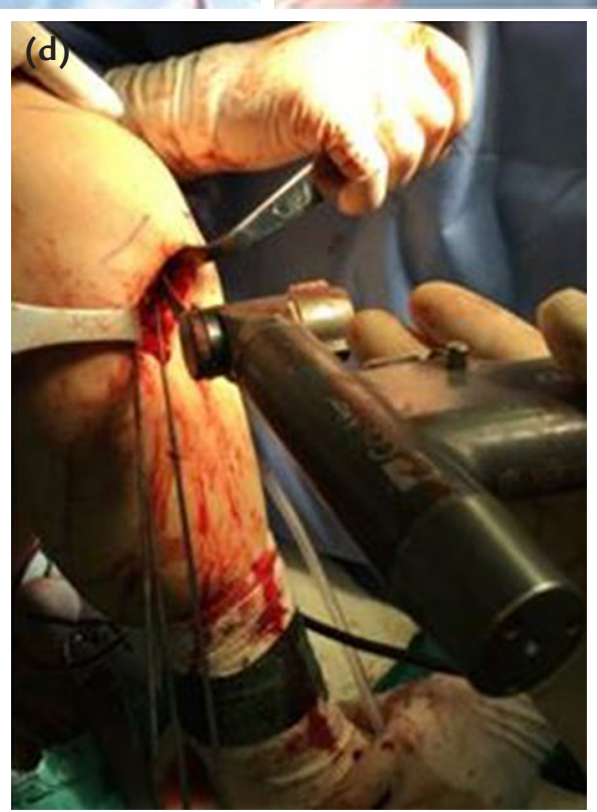

Şekil 5. a-d. Ameliyat esnasında klinik görüntüler (a, b). Distal femur osteotomisi (c) ve proksimal tibia osteotomisi (d). 


\section{KAYNAKLAR}

1. Jackson JP, Waugh W. Osteotomy for Osteoarthritis of the Knee. In: Proceedings of the Sheffield Regional Orthopaedic Club. J Bone Joint Surg 1958;40-B:826.

2. Coventry MB. Osteotomy of the upper portion of the tibia for degenerative arthritis of the knee. A preliminary report. J Bone Joint Surg Am 1965; 47(5):984-90. Crossref

3. Lexer E. Revascularization Osteotomy 1931, 2nd ed. Barth JA.

4. Jackson JP, Waugh W. Tibial Osteotomy for Osteoarthritis of the Knee. J Bone and Joint Surg Br 1961;43-B:746-51.

5. Benjamin A. Double osteotomy for the painful knee in rheumatoid arthritis and osteoarthritis. J Bone Joint Surg $\mathrm{Br}$ 1969;51-B(4):694-9. Crossref

6. Saragaglia D, Mercier N, Colle PE. Computer-assisted osteotomies for genu varum deformity: which osteotomy for which varus? Int Orthop 2010;34(2):185-90. Crossref

7. Babis GC, An KN, Chao EY, Rand JA, Sim FH. Double level osteotomy of the knee: a method to retain joint-line obliquity. Clinical results. J Bone Joint Surg Am 2002;84(8):1380-8. Crossref

8. Saragaglia D, Blaysat M, Mercier N, Grimaldi M. Results of forty-two computer-assisted double level osteotomies for severe genu varum deformity. Int Orthop 2012, 36(5):9991003. Crossref

9. Nakayama H, Schroter S, Yamamoto C, Iseki T, Kanto R, Kurosaka K, Kambara S, Yoshiya S, Higa M. Large correction in opening wedge high tibial osteotomy with resultant joint-line obliquity induces excessive shear stress on the articular cartilage. Knee Surg Sports Traumatol Arthrosc 2018;26(6):1873-8. Crossref

10. Kambara S, Nakayama H, Kanto R, Yoshiya S. Comparative analysis of change in rotational alignment after double level osteotomy and opening wedge high tibial osteotomy. Asia-Pacific J Sports Med Arthrosc Rehab Tech 2017;9:38. Crossref
11. Lobenhoffer P, Van Heerwaarden RJ, Staubli AE, Jacob RP. Osteotomies around the knee: indications-planning-surgical techniques using plate fixators. Thieme; 2011.

12. Paley D, Pfeil J. Principles of deformity corrections around the knee. Orthopäde 2000;29(1):18-38. Crossref

13. Schroter S, Nakayama H, Yoshiya S, Stockle U, Ateschrang A, Gruhn J. Development of the double level osteotomy in severe varus osteoarthritis showed good outcome by preventing oblique joint line. Arch Orthop Trauma Surg 2019;139(4):519-27. Crossref

14. Yasuda K, Majima T, Tsuchida T, Kaneda K. A ten-to 15year follow-up observation of high tibial osteotomy in medial compartment osteoarthrosis. Clin Orthop Relat Res 1992;(282):186-95. Crossref

15. Trieb K, Grohs J, Hanslik-Schnabel B, Stulnig T, Panotopoulos J, Wanivenhaus A. Age predicts outcome of high-tibial osteotomy. Knee Surg Sports Traumatol Arthrosc 2006;1;14(2):149-52. Crossref

16. Saragaglia D, Chedal-Bornu B, Rouchy RC, Rubens-Duval B, Mader R, Pailhe R. Role of computer-assisted surgery in osteotomies around the knee. Knee Surg Sports Traumatol Arthrosc 2016;24(11):3387-95. Crossref

17. Lobenhoffer P. Importance of osteotomy around to the knee for medial gonarthritis. Indications, technique and results. Orthopade 2014;43(5):425-31. Crossref

18. Elmalı N, Esenkaya I, Can M, Karakaplan M. Monoplanar versus biplanar medial open-wedge proximal tibial osteotomy for varus gonarthrosis: a comparison of clinical and radiological outcomes. Knee Surg Sports Traumatol Arthrosc 2013;1;21(12):2689-95. Crossref 